\title{
Evaluation of Devasthal site for optical astronomical observations
}

\author{
R. Sagar, C.S. Stalin, A.K. Pandey, W. Uddin, V. Mohan, B.B. Sanwal, S.K. Gupta, R.K.S. Yadav, A.K. Durgapal, \\ S. Joshi, Brijesh Kumar, A.C. Gupta, Y.C. Joshi, J.B. Srivastava, U.S. Chaubey, M. Singh, P. Pant, and K.G. Gupta \\ U. P. State Observatory, Manora Peak, Nainital 263 129, India
}

Received May 20, 1999; accepted March 7, 2000

\begin{abstract}
Based on an extensive site survey conducted during 1980-1990 in the Shivalik Hills of the Central Himalayan range, a promising site Devasthal has been identified. The longitude and latitude of Devasthal Peak are $79^{\circ} 41^{\prime} \mathrm{E}$ and $29^{\circ} 23^{\prime} \mathrm{N}$. It is situated at an altitude of $2540 \mathrm{~m}$ and about $50 \mathrm{~km}$ by road from Nainital towards East. The surroundings of Devasthal are thinly populated and it is logistically well suited for establishing modern optical observational facilities. The prevailing wind direction at Devasthal is NW. For a large fraction of the night time, variation in the ambient temperature was less than a degree and wind speed was less than $10 \mathrm{~m} / \mathrm{s}$. During spectroscopic nights (> 200 in a year) relative humidity is less than $80 \%$ for about $70 \%$ of the time. During 1997 and 1998 seeing measurements using differential image motion techniques have been carried out close to ground at two locations namely Site 1 and Site 2 in Devasthal. Our observations for Site 1 carried over 88 nights yield a median seeing value of 1". 4 . For Devasthal Site 2 observations carried over 37 nights yield a median seeing value of $1^{\prime \prime} 1$. Devasthal Site 2 has therefore been selected for locating a modern $3 \mathrm{~m}$ optical telescope.
\end{abstract}

Key words: site testing — atmospheric effects

\section{Introduction}

According to diffraction theory, the image of a point source produced by a telescope of diameter $D$ at a wavelength $\lambda$ is an Airy's disc of size $\varepsilon_{D} \sim \lambda / D$. Due to degradation by the Earth's atmosphere the stellar image formed at the focus of the ground based telescope is much bigger than $\varepsilon_{D}$. The size of the image also depends on the thermal effects of the dome, building and immediate surroundings as well as local atmospheric turbulence which depends on the location of the site. We refer here to seeing

Send offprint requests to: R. Sagar, e-mail:sagar@upso.ernet.in
( $F W H M$ of a star image) as the overall quality of the optical image. For many purposes the power of a telescope is therefore proportional to the primary collecting area divided by the solid angle formed by the image and thus a $2.5 \mathrm{~m}$ telescope with 0.5 seeing is equivalent in performance to a $5 \mathrm{~m}$ telescope with $1^{\prime \prime} 0$ seeing (Woolf 1982). Hence, smaller telescopes situated at sites with good seeing can perform better than larger telescopes located at sites with poorer seeing. Thus, it is of primary importance to evaluate a site before putting up a large telescope and the same has been carried out here for locating a modern $3 \mathrm{~m}$ class optical telescope jointly by Uttar Pradesh State Observatory (UPSO), Nainital and Tata Institute of Fundamental Research (TIFR), Mumbai.

The principal requirements of a site for optical astronomical observations are clear, dark and transparent skies with good seeing, modest atmospheric extinction, low precipitable water vapour, small changes in night time air temperature etc. In addition, the site should be far away from human activities so that for at least a few decades the deterioration due to light and atmospheric pollution is minimal. At the same time, one has to take into account the logistics of access and availability of water and power to the site so that infrastructural development and telescope operation do not become too expensive. The cost involved in providing easy accessibility to an otherwise excellent site often comes in the way of its choice. A compromise between the factors mentioned above is always made. Consequently, there are only a few excellent astronomical sites on the Earth. Most of them are located either on island (such as Hawaii and La Palma) or on coastal areas (such as Chilean and Midwest American). Good sites are generally located in the subtropical zone (25 to 35 positive or negative latitudes) and are mostly located at heights $\geq 2 \mathrm{~km}$ above the mean sea level.

\section{Search for an astronomical site in India}

The occurrence of monsoon and winter cyclones render very large tracts of India unfavourable for astronomical 

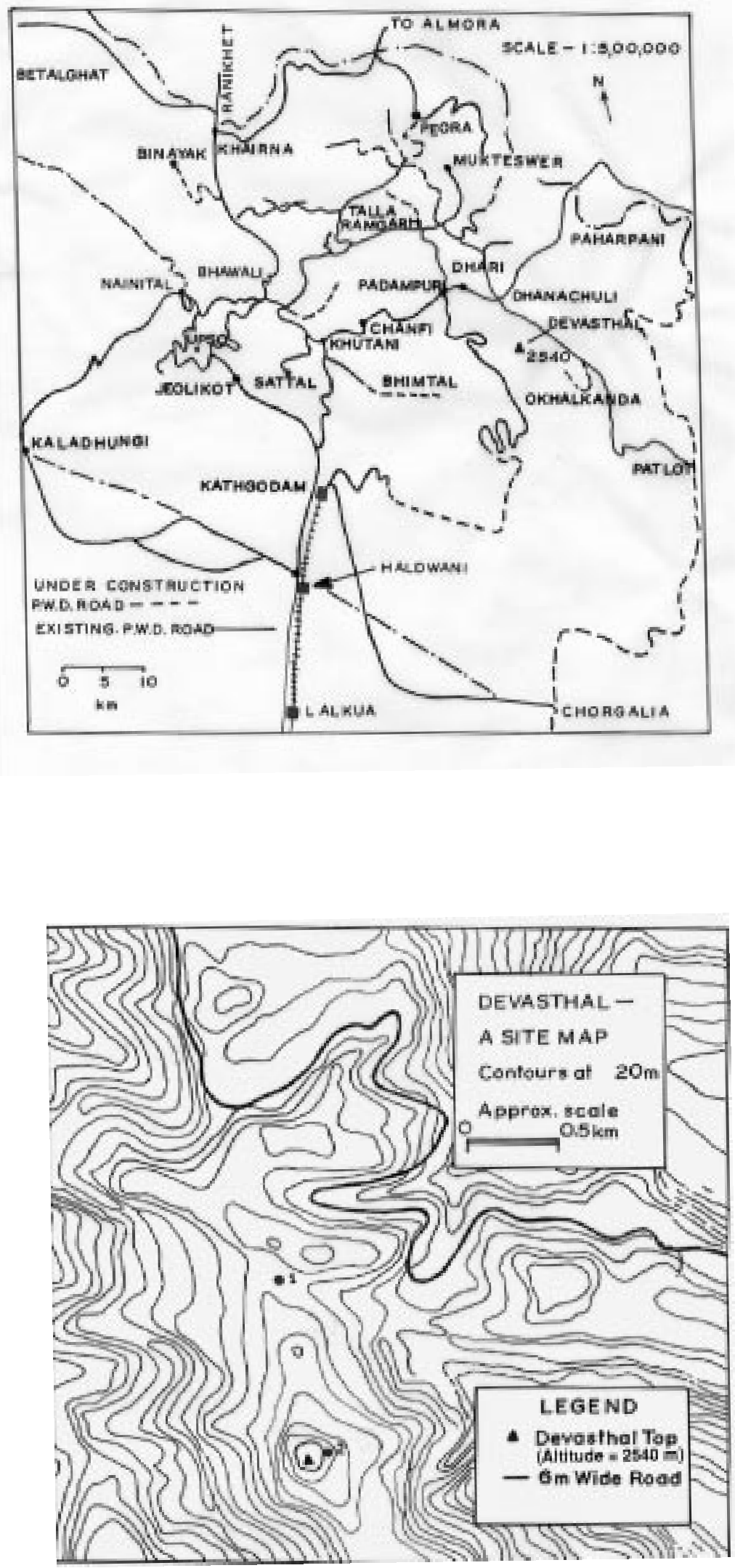

Fig. 1. The upper and lower panels of the diagram show the location and contour maps of Devasthal region. Site 1 and Site 2 are marked as 1 and 2 respectively 
sites. Distribution of the number of clear (cloud free) skies in a year over India has been given earlier by Bappu et al. (1978) using ground based meteorological data. Recently, Sapru et al. (1998) have obtained the average annual spectroscopic nights for a number of places in India using the INSAT satellite cloud imagery database for the period 1989 to 1994. In India, maximum number of spectroscopic nights are at Gurushikhar, Mt. Abu in Rajasthan, though it does not have all the advantages from altitude point of view and is also affected by dust and light pollution. On the other hand sites in the Shivalik ranges of central Himalayas have these advantages as well as the number of spectroscopic nights are over 200 in a year.

Manora Peak, just south of Nainital, headquarters of UPSO is located in Shivalik range at an altitude of $1950 \mathrm{~m}$. It started functioning in late fifties. With time, light pollution at the present location has increased significantly. Seeing at the present site is also generally poor $\left(\geq 11^{\prime \prime} 5\right)$. The site survey work to select a better site in Kumaon and Garhwal regions of Shivalik Himalayas (Uttar Pradesh) for setting up a moderate size optical telescope was therefore initiated in 1980. For this, contour maps (1:50000) of these regions provided by the Survey of India were studied and a total of six reconnaisance trips were made to 36 sites during 1981-82. Based on altitude of the site and its obstructions, if any, due to nearby hills, terrain of the surrounding regions and logistic reasons, like availability of reasonably flat land and/or presence of suitable water source at a manageable level, distance from the existing $6 \mathrm{~m}$ wide metalled road and possible disturbance likely to be caused by nearby city lights in foreseeable future, a total of four suitable sites namely Gananath, Mornaula, Devasthal and Chaukori (having altitude $\geq 2 \mathrm{~km}$ ) were identified for preliminary investigations. Meteorological observations at these four sites were carried out during 1982-1991. The meteorological equipments installed at these stations were thermograph, hygrograph, barograph, sunshine recorder, rain gauge, snow gauge and wind speed and direction recorder. The cloudiness was recorded visually by the observers. Following are the findings of the site survey.

\subsection{Meteorological parameters}

Results of the meteorological observations for the four sites studied have been summarised in Table 1 and are discussed below.

\subsubsection{Stability of night time temperature}

The temperature measurements were made with a continuous recording type thermograph at each site. The variation in night time temperature is minimum for Devasthal site. The analysis of night time temperature data indicates that the temperature variation during night is within $2^{\circ} \mathrm{C}$ for more than $60 \%$ of the time for all the sites except Chaukori. From this point of view, Devasthal is the most suitable site.

\subsubsection{Relative humidity}

Continuous recording hygrograph was used to measure relative humidity at a site. The yearly relative humidity measurements show that during photometric nights, humidity generally remains below $60 \%$ at Devasthal and Mornaula and below $70 \%$ at Gananath and Chaukori. However, during monsoon months, it is generally higher than $80 \%$ for most of the time at all the sites.

\subsubsection{Atmospheric pressure}

The atmospheric pressure was recorded with a continuous recording barograph. The data indicates that the pressure variation during night at all sites is generally within $1 \mathrm{mb}$ and hence they are similar from this point of view.

\subsubsection{Wind speed}

The wind speed and direction were recorded with a continuous recording anemograph installed at a height of about $5 \mathrm{~m}$ from the ground level. The maximum wind speed during night time was found to be generally $6 \mathrm{~m} / \mathrm{s}$. It is found that more than $75 \%$ of night hours have wind speed below $3 \mathrm{~m} / \mathrm{s}$ at Devasthal and Gananath. The prevailing wind direction at both places is NW.

\subsection{Cloud coverage}

The visual observations of cloud coverage were recorded at four hourly intervals. Based on these data, cloud coverage during the night time was estimated. The night time was defined as the duration between end of evening astronomical twilight to start of morning astronomical twilight. Following criteria had been adopted for cloud coverage

1. Clear night: When the cloud cover is zero for the complete night;

2. Partly clear night: When the cloud cover is zero for more than four consecutive hours;

3 . Night $<3$ Octas: When the cloud cover is $<3$ octas for more than four consecutive hours;

4. Cloudy nights are other than (1), (2) and (3);

5. Photometric nights include (1) and (2);

6. Spectroscopic nights include (1), (2) and (3).

These observations indicate that spectroscopic nights at all the four sites are $\geq 200$ in a year. A large fraction of them $(\geq 85 \%)$ are of photometric quality. Here it is 
Table 1. Preliminary survey parameters for the four sites investigated

\begin{tabular}{cccccccc}
\hline Site & $\begin{array}{c}\text { Altitude } \\
(\mathrm{m})\end{array}$ & $\begin{array}{c}\text { Duration of } \\
\text { observations } \\
\text { (year) }\end{array}$ & $\begin{array}{c}\text { Annaul } \\
\text { variation } \\
\text { in night } \\
\text { temperature } \\
\left({ }^{\circ} \mathrm{C}\right)\end{array}$ & $\begin{array}{c}\text { temperature } \\
\text { variation } \\
\leq 2{ }^{\circ} \mathrm{C}\end{array}$ & $\begin{array}{c}\text { \% of nights having } \\
\text { pressure } \\
\text { variation } \\
\leq 1 \mathrm{mb}\end{array}$ & $\begin{array}{c}\text { wind } \\
\text { speed } \\
\leq 3 \mathrm{~m} / \mathrm{s}\end{array}$ & $\begin{array}{c}\text { prevailing } \\
\text { wind } \\
\text { direction }\end{array}$ \\
\hline Chaukori & 2130 & $1982-1989$ & 27 to -3 & 44 & 87 & - & $\mathrm{NNW}$ \\
Devasthal & 2540 & $1986-1991$ & 21.5 to -4.5 & 73 & 89 & 77 & $\mathrm{NW}$ \\
Gananath & 2090 & $1982-1990$ & 24 to -3 & 71 & 92 & 82 & $\mathrm{NW}$ \\
Mornaula & 2250 & $1984-1990$ & 24 to -3 & 62 & 88 & 62 & $\mathrm{NW}$ \\
\hline
\end{tabular}

important to mention that a recent study based on the INSAT satellite cloud imagery database for the period 1989 to 1994 (Sapru et al. 1998) suggest that the average annual percentage of spectroscopic nights is about $55 \%$ for Devasthal which is in agreement with the visual ground based observations. These numbers are comparable to those observed at high altitude $(\geq 2 \mathrm{~km})$ sites in India (HIROT team 1996, Bhatt et al. 2000). A comparison of spectroscopic nights at all sites vis-à-vis some well known sites around the world such as Siding Spring in Australia (65\%, Sadler et al. 1991), La Palma in Spain (80\%, Murdin 1985), Cerro Tololo and La Silla in Chile (82\%, Tapia 1992), Mauna Kea in U.S.A. (73\%, Tapia 1992) and San Pedro Mártir in New Mexico (80\%, Tapia 1992) indicates that all the sites can be called satisfactory.

\section{Description of Devasthal sites}

Amongst the four sites mentioned above, Devasthal was chosen for further in depth study based on the criteria such as logistics, altitude, approachability and local topography conducive to good seeing. It is worth mentioning that there are no mountain ranges higher than Devasthal peak within an aerial radius of $1 \mathrm{~km}$ which can create turbulence and thus degrade the seeing. As the name Devasthal in Hindi language means place of God, there is an ancient Shiva (one of Hindu Gods) temple at the highest point of this region. The geographical and contour maps of Devasthal region are shown in Fig. 1. This site except for the last $3-4 \mathrm{~km}$ is connected to major towns (e.g. Nainital, Kathgodam and Haldwani) by a $6 \mathrm{~m}$ wide metalled road. It is far away from any urban development and therefore light contamination is virtually nil. Two potential sites for locating the modern optical telescope were identified. This selection is primarily based on logistics, not to disturb the location of the temple at Devasthal top, apart from being relatively free from trees. The two sites which are separated by about $1.5 \mathrm{~km}$ from each other are hereinafter referred as Site 1 and Site 2. Using a GPS clock unit accurate geographical coordinates of Devasthal Site 1 have been determined. The altitude is $2420 \pm 5 \mathrm{~m}$, while longitude and latitude are $79^{\circ} 40^{\prime} 57^{\prime \prime} \mathrm{E} \pm 1^{\prime \prime}$ and $29^{\circ}$ $22^{\prime} 46^{\prime \prime} \mathrm{N} \pm 1^{\prime \prime}$ respectively. It is about $1.5 \mathrm{~km}$ from the metalled road. Sufficient amount of water is available from natural springs near this site. Site 2 is close to Devasthal peak and is about $120 \mathrm{~m}$ higher than Site 1.

The theory of seeing along with the observations carried out at Devasthal are given in the following sections.

\section{Theory of seeing}

The relationship between the full width at half maximum $(F W H M)$ of a stellar image point spread function (PSF) formed at the focus of a large telescope and Fried parameter $r_{0}$, is given by Dierickx (1992) as

$\epsilon_{F W H M}=\frac{0.98}{r_{\mathrm{o}}} \lambda$,

where $\lambda$ is the wavelength. The value of $r_{\mathrm{o}}$ represents the diameter of the telescope for which diffraction limited image resolution is equal to the $F W H M$ of the seeing limited image (cf. Fried 1966).

The variance $\left(\sigma^{2}\right)$ of the two dimensional image position is (cf. Vernin \& Muñoz-Tuñón 1995) given as

$\sigma^{2}=0.373 \epsilon_{F W H M}^{2}\left(\frac{r_{0}}{D}\right)^{1 / 3}$.

Thus measuring the image motion at the focus of a telescope of aperture $D$ and at wavelength $\lambda$, the Fried parameter $r_{0}$ and hence the seeing can be deduced from Eq. (1). This technique of measuring image motion suffers from the erratic motion of the telescope and it is difficult to separate the image motions due to turbulence and those due to telescope, which includes wind shaking, guiding and dome effect etc. The differential image motion monitor (DIMM) measurements eliminate the effects due to the motion of the telescope and hence enables one to measure the contributions of the atmosphere to the image degradation. The DIMM principle is to produce twin images of a star with the same telescope via two entrance pupils separated by a fixed distance. The assumption that Kolmogorov turbulence theory accurately describes the effects of atmosphere upon images, enables us to assess the longitudinal and transverse (parallel and perpendicular to the aperture alignment) variance of the differential image motion. The variance of the image motion in the direction parallel to 
Table 2. Instruments used in the survey and their technical characteristics

\begin{tabular}{|c|c|}
\hline Seeing & \\
\hline Data handling & Pentium PC's \\
\hline Telescope (Site 1) & $\begin{array}{l}52 \mathrm{~cm} ; f \text { ratio }=13 \\
\text { Fork mounting }\end{array}$ \\
\hline Telescope (Site 2) & $\begin{array}{l}38 \mathrm{~cm} ; f \text { ratio }=15 \\
\text { Single pier mounting }\end{array}$ \\
\hline Camera at each site & $\begin{array}{l}\text { CCD }(\mathrm{ST} 4) ; \text { size }=192 \times 165 \text { pixels }^{2} \\
\text { pixel size }=13.74 \mu \times 16.0 \mu\end{array}$ \\
\hline Power supply (DIMM) & Generators \\
\hline Date acquisition rate & every 10 millisecond \\
\hline Meteorology & \\
\hline Meteorological all & Wind speed $( \pm 0.1 \mathrm{~m} / \mathrm{s})$ \\
\hline weather station & Wind direction ( \pm 1 degree) \\
\hline Configuration & Relative humidity $( \pm 1 \%)$ \\
\hline Availability & Air temperature $\left( \pm 0.01^{\circ} \mathrm{C}\right)$ \\
\hline & Solar radiation $\left( \pm 0.001 \mathrm{w} / \mathrm{m}^{2}\right)$ \\
\hline & Soil temperature $\left( \pm 0.1^{\circ} \mathrm{C}\right)$ \\
\hline & Rainfall $( \pm 0.25 \mathrm{~cm})$ \\
\hline Data acquisition rate & 1 hour \\
\hline Power supply (AWS) & Batteries \\
\hline Microthermal tower & $\begin{array}{l}20 \mathrm{~m} \text { tower and three sensors } \\
\text { placed at heights of } 6,12 \text { and } 18 \mathrm{~m}\end{array}$ \\
\hline Data acquisition rate & every $1 \mathrm{~s}$ \\
\hline
\end{tabular}

the line joining the subapertures is given by (see Sarazin \& Roddier 1990)

$\sigma_{1}^{2}=2 \lambda^{2} r_{0}^{-5 / 3}\left(0.179 S^{-1 / 3}-0.0968 d^{-1 / 3}\right)$,

where $S$ is the diameter of the two entrance pupils and $d$ is the separation between them. The corresponding expression for the differential image motion perpendicular to the line joining the two apertures is

$\sigma_{\mathrm{t}}^{2}=2 \lambda^{2} r_{0}^{-5 / 3}\left(0.179 S^{-1 / 3}-0.145 d^{-1 / 3}\right)$.

It should be noted that these relations are valid if $S / d$ $\leq 0.5$ (Sarazin \& Roddier 1990 and references therein). Measuring $\sigma_{\mathrm{t}}$ and $\sigma_{\mathrm{l}}$ enables us to estimate the respective $r_{0}$, which when used in Eq. (1) gives the longitudinal and transverse seeing respectively. In the present case the value of $\mathrm{S} / \mathrm{d}$ is 0.15 and 0.21 for $52 \mathrm{~cm}$ and $38 \mathrm{~cm}$ telescopes respectively.

\section{Characterization of Devasthal site}

As a follow up on the site survey reported above, precipitable water vapour, meteorological and astronomical seeing measurements were carried at Devasthal sites. Primary emphasis was placed on the evaluation of ground level seeing at the two sites mentioned above. Simultaneous

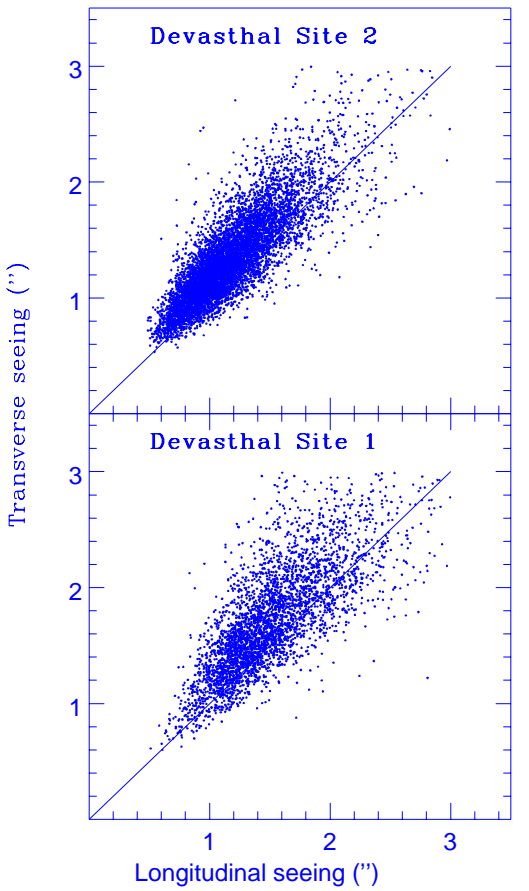

Fig. 2. A comparison of longitudinal and transverse seeing for the two sites in Devasthal. Straight line has unit slope and zero intercept

measurements of atmospheric parameters such as air temperature, soil temperature, solar radiation, relative humidity and wind speed and direction as well as microthermal measurements were performed at Site 1 . These parameters are of major importance in the interpretation of the occurrence of optical turbulence.

\subsection{Estimation of precipitable water vapour}

The precipitable water vapour content in the atmosphere was measured with the instrument designed and built by Prof. Westphal and kindly loaned to UPSO. The observations were taken between January 1989 to June 1989 at Devasthal. They indicate $1-2 \mathrm{~mm}, 2-3 \mathrm{~mm}$ and $>3 \mathrm{~mm}$ of precipitable water vapour for $21 \%, 43 \%$ and $36 \%$ of the time respectively.

\subsection{DIMM instrumental setup and observations}

This section describes the DIMM instruments which were built in UPSO laboratories and used for seeing measurements along with the procedure used for data processing. Differential image motion technique has been used as early as 1960 to provide quantitative seeing estimates. Such work carried out in recent years include those by the European Southern Observatory (Sarazin \& Roddier 1990), the National Optical Astronomical Observatories (Forbes et al. 1988), the ESO site testing measurements 


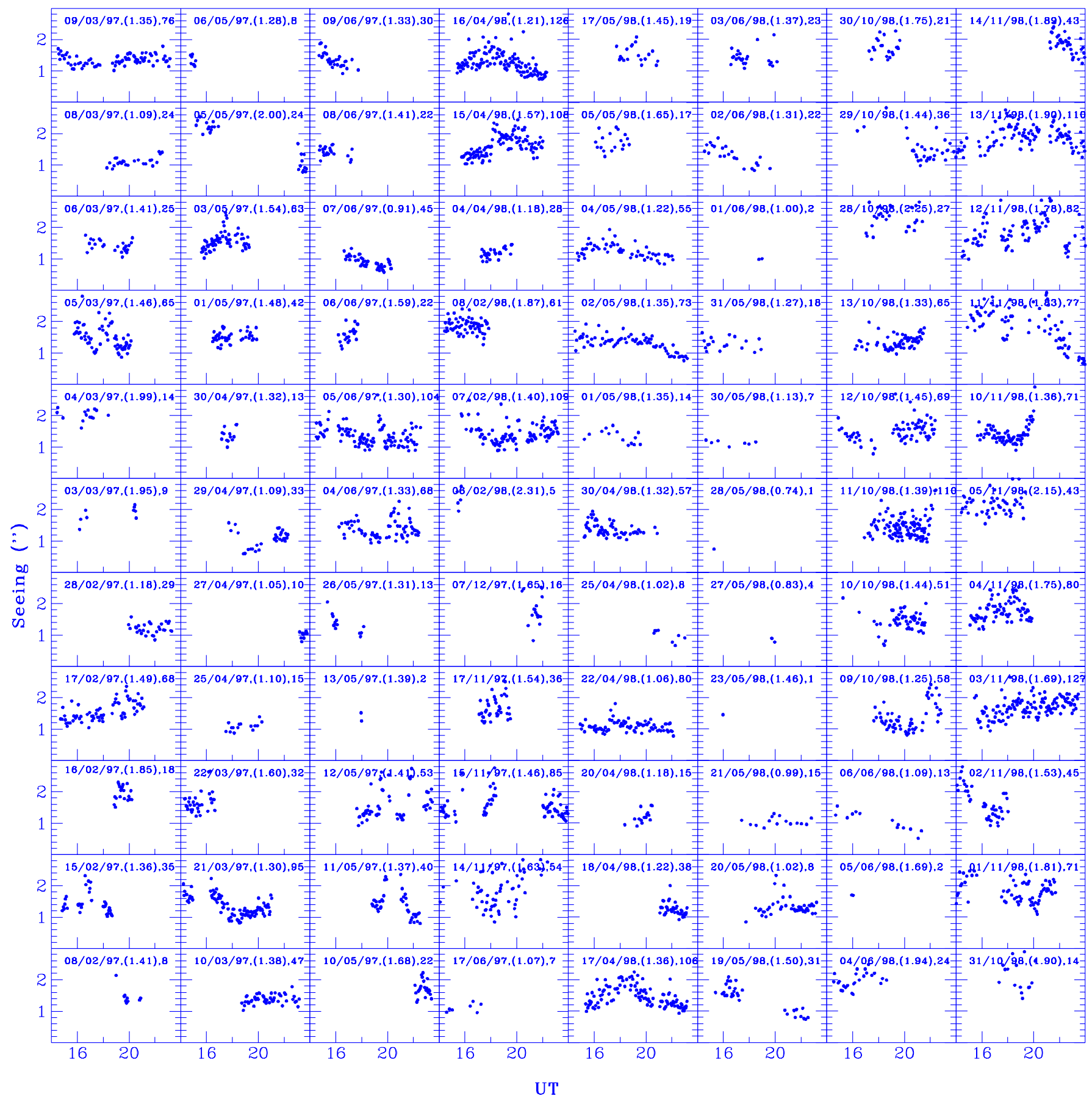

Fig. 3. Seeing at Devasthal Site 1 plotted against UT. The date of observation along with the median seeing value (inside bracket) and the number of points are indicated sequentially on each panel

for the Very Large Telescope (Pedersen et al. 1988), Observatorio del Roque de los Muchachos (ORM ) at La Palma (Vernin \& Muñoz-Tuñón 1995) etc. for the evaluation of potential observing sites. The principles in detail of DIMM instrument can be found in Sarazin \& Roddier (1990).

A $52 \mathrm{~cm}$ telescope with an equatorial fork mounting having a plate scale of $31^{\prime \prime} / \mathrm{mm}$ at the $\mathrm{f} / 13$ folded Cassegrain focus is used at Site 1 , whereas at Site 2, a
$38 \mathrm{~cm}$ telescope with single pier mounting having a plate scale of $36^{\prime \prime} / \mathrm{mm}$ at the $\mathrm{f} / 15$ Cassegrain focus is used. The front portion of the $52 \mathrm{~cm}$ reflector tube is covered by a mask which has two circular holes, each of $6 \mathrm{~cm}$ diameter and separated by $40 \mathrm{~cm}$. Similarly, the $38 \mathrm{~cm}$ reflector is covered by a mask having two circular holes each of $5 \mathrm{~cm}$ in diameter and separated by $24 \mathrm{~cm}$. One of the holes contains a prism which deviates the incoming parallel light of a star by about $30^{\prime \prime}$ in the direction joining 
the line of the centers of the two holes, so that two images of the same star are formed on the CCD detector. The telescopes are equipped with a PC which controls the Santa Barbara Instrument Group (SBIG) ST4 autoguiding CCD camera and thus accumulates image motion data and analyse them online to provide seeing measurements in two mutually perpendicular directions. One pixel of the CCD corresponds to 0 '. $42 \times 0$ ". 49 at $52 \mathrm{~cm}$ telescope and $0^{\prime \prime} .50 \times 0$. .'58 at $38 \mathrm{~cm}$ telescope. Our setup closely follows that of Wood et al. (1995). The details of the instruments used in the seeing campaign and their characteristics are given in Table 2.

In DIMM, a series of exposures each spanning a period of $10 \mathrm{~ms}$ are taken and hundred such exposures are used to derive one estimate of the standard deviation of the relative separation of the images, $\sigma_{\mathrm{l}}$ and $\sigma_{\mathrm{t}}$ parallel and perpendicular to the line joining the centres of the two apertures. Using Eqs. (3) and (4) one can then find independent estimates of $r_{0}$. These independent values of $r_{0}$ are then converted into seeing estimates using Eq. (1) and a wavelength of $5000 \AA$. All the above processes are done online and the data are stored in the $\mathrm{PC}$ for further analysis. The data obtained using DIMM were then corrected for airmass $(X)$ using the relation

$$
F W H M_{\text {corrected }}=F W H M_{\text {observed }}(1 / X)^{3 / 5} \text {. }
$$

The use of this correction is necessary as it allows comparisons to be made with observations obtained at different time in various directions.

\subsection{Estimation of errors}

\subsubsection{System noise}

The uncertainty in the determination of centroid of an image due to detector noise introduces an error in the seeing measurements. Since this instrumental noise is not correlated with the true nature of the atmosphere, this has to be subtracted out before an estimation of the seeing is made (cf. Sarazin \& Roddier 1990). The estimation of the instrumental noise was carried out experimentally in the optics lab of UPSO. The intensity levels of the images were kept similar to those that we maintain in performing seeing measurements. The uncertainty measured in the separation of the images of two pin holes on the CCD detector gives a value of 0.09 pixel. This system noise when taken into account improves our seeing reported here by $0^{\prime \prime} 01$ only.

\subsubsection{Statistical errors}

The statistical errors of the seeing measurements were calculated using the formalism given by Frieden (1983). It has been pointed out by Sarazin \& Roddier (1990) that the statistical properties of the atmosphere does not change

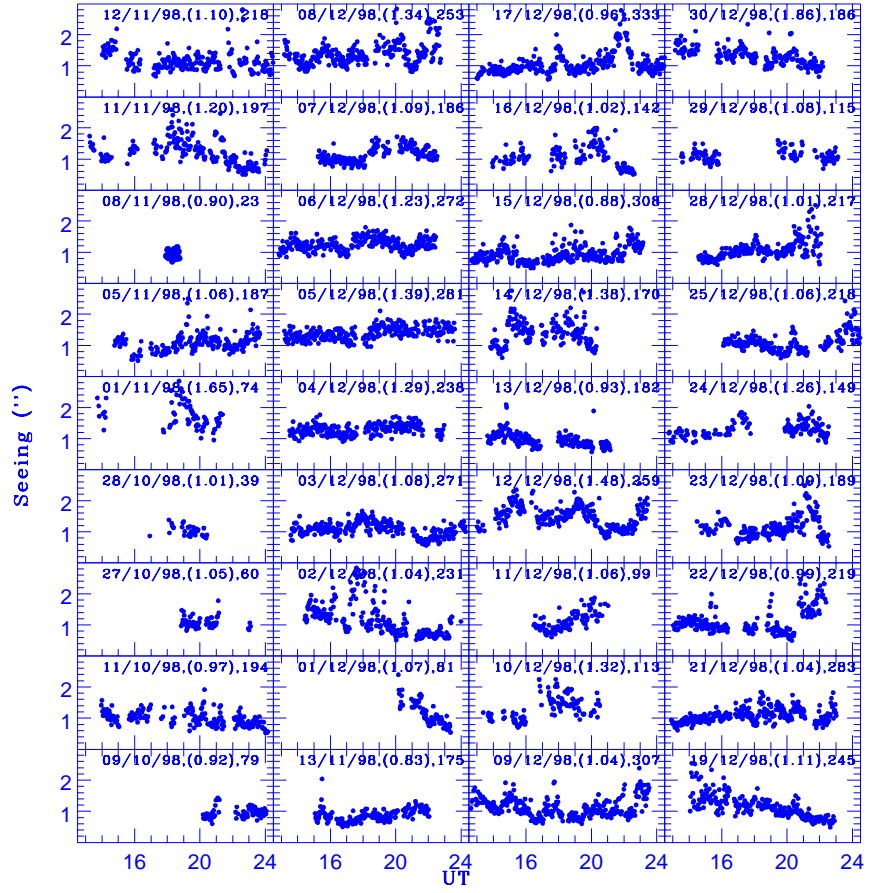

Fig. 4. Seeing at Devasthal Site 2 plotted against UT. Other details are the same as in Fig. 3

for about a minute. Under typical seeing measurements at Devasthal we are able to process about 50 images in a minute. The number of images obtained in a minute is limited by the exposure time as well as the readout time of the CCD. For our measurements the statistical error turns out to be $12 \%$, and the error for each individaul measurement is about $9 \%$.

\subsection{Comparison of longitudinal and transverse seeing}

For ESO DIMM the seeing values obtained from $\sigma_{\mathrm{l}}$ and $\sigma_{\mathrm{t}}$ agree with each other within $12 \%$ (see Sarazin \& Roddier 1990). An attempt has been made by us to see the behaviour of longitudinal and transverse seeing for the observations at Devasthal sites. The seeing measurements were carried out for 88 nights at Site 1 during February 1997 and November 1998, and for 37 nights at Site 2 between October and December 1998. In Fig. 2 we have plotted the longitudinal seeing against the transverse seeing for both Devasthal sites. For comparison, we have drawn a line of unit slope and zero intercept. This indicates a fairly good agreement between the two measurements considering the errors discussed above. Amongst the two independent measurements, we have therefore considered only one, namely the longitudinal component as the seeing of the site. There is however some difference between the values obtained from the two components of image motion; wind speed and the finite outer scale length will affect the 
Table 3. Results of seeing measurements at Devasthal

\begin{tabular}{lccccc}
\hline Month & No.of & $\begin{array}{c}\text { No.of } \\
\text { observations }\end{array}$ & \multicolumn{3}{c}{ seeing in arcsecond } \\
& Mean & Std.dev & Median \\
\hline Site 1 & & & & & \\
$02-97$ & 159 & 5 & 1.5 & 0.3 & 1.4 \\
$03-97$ & 387 & 9 & 1.4 & 0.3 & 1.4 \\
$04-97$ & 71 & 4 & 1.1 & 0.3 & 1.1 \\
$05-97$ & 267 & 9 & 1.5 & 0.4 & 1.5 \\
$06-97$ & 298 & 7 & 1.3 & 0.3 & 1.3 \\
$11-97$ & 174 & 3 & 1.6 & 0.4 & 1.5 \\
$12-97$ & 16 & 1 & 1.8 & 0.5 & 1.7 \\
$02-98$ & 175 & 3 & 1.6 & 0.4 & 1.6 \\
$04-98$ & 566 & 9 & 1.3 & 0.3 & 1.3 \\
$05-98$ & 299 & 13 & 1.3 & 0.3 & 1.3 \\
$06-98$ & 86 & 6 & 1.5 & 0.4 & 1.4 \\
$10-98$ & 451 & 9 & 1.5 & 0.4 & 1.4 \\
$11-98$ & 749 & 10 & 1.8 & 0.4 & 1.8 \\
\hline Site 2 & & & & & \\
$10-98$ & 389 & 5 & 1.0 & 0.2 & 1.0 \\
$11-98$ & 873 & 6 & 1.1 & 0.4 & 1.1 \\
$12-98$ & 5536 & 26 & 1.2 & 0.3 & 1.1 \\
\hline
\end{tabular}
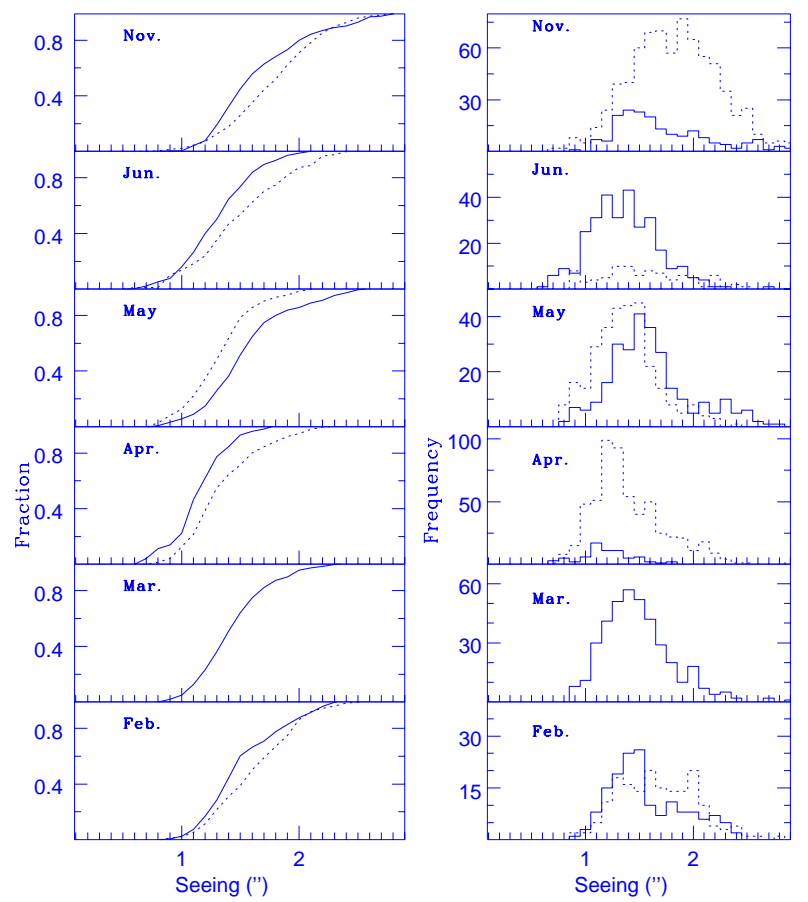

Fig. 5. Cumulative distribution and histogram of seeing measured during the indicated month at Devasthal Site 1. The solid and dotted lines are for the year 1997 and 1998 respectively
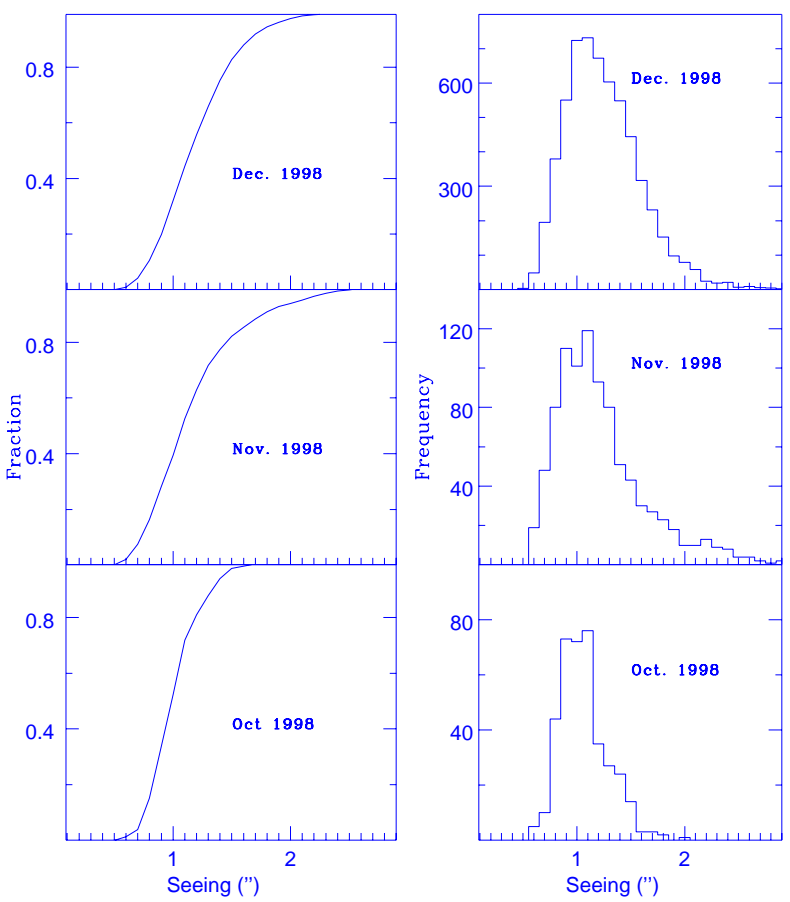

Fig. 6. Cumulative distribution and histogram of seeing measured during the indicated month at Devasthal Site 2
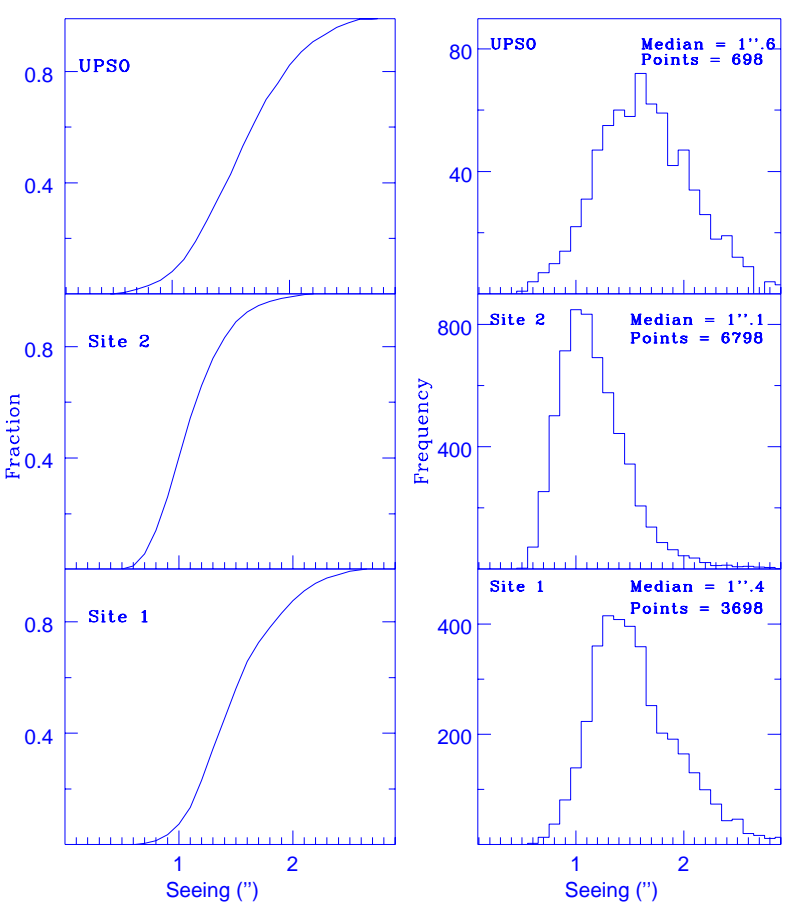

Fig. 7. Cumulative distribution and histogram of entire seeing measurements obtained at UPSO and Devasthal sites 

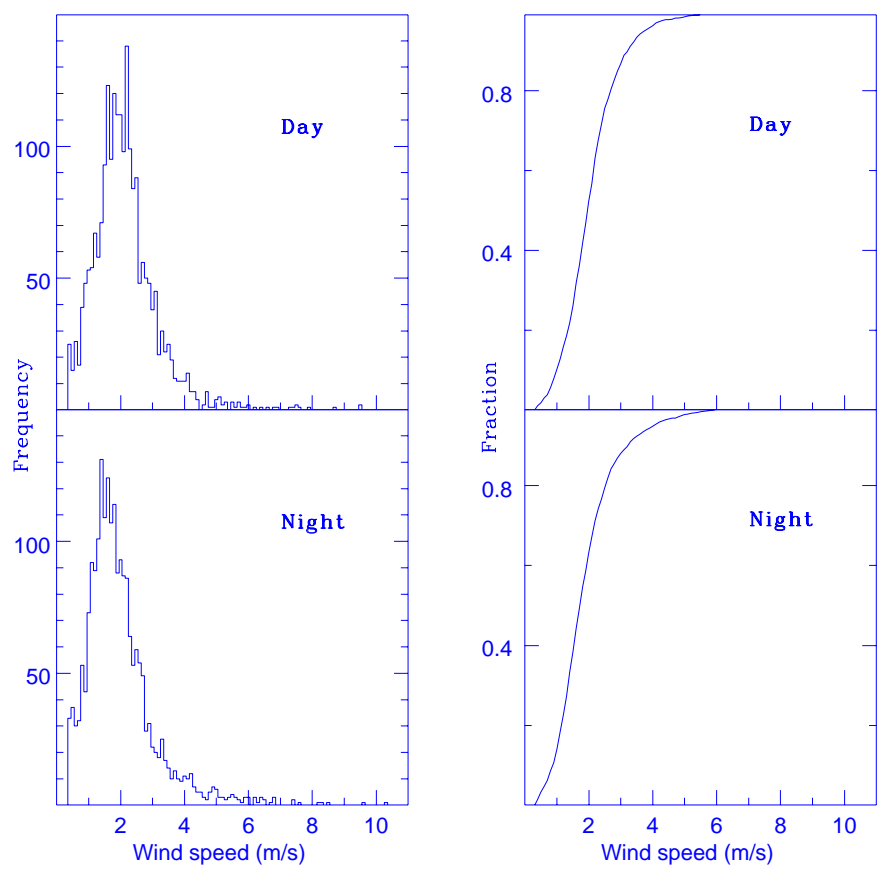

Fig. 8. Histogram and cumulative distribution of the wind speed at Devasthal Site 1

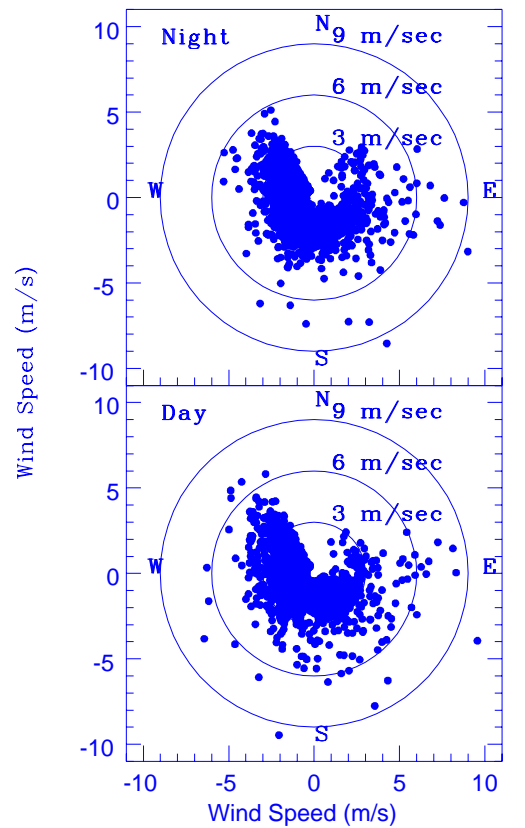

Fig. 9. Distribution of wind speed and direction at Devasthal Site 1

correlation between the two apertures and could lead to this difference (see Das et al. 1999).

\subsection{Seeing measurements}

Seeing measurements were carried out for 88 and 37 nights at Site 1 (during February 1997 to November 1998) and Site 2 (between October and December 1998) respectively.

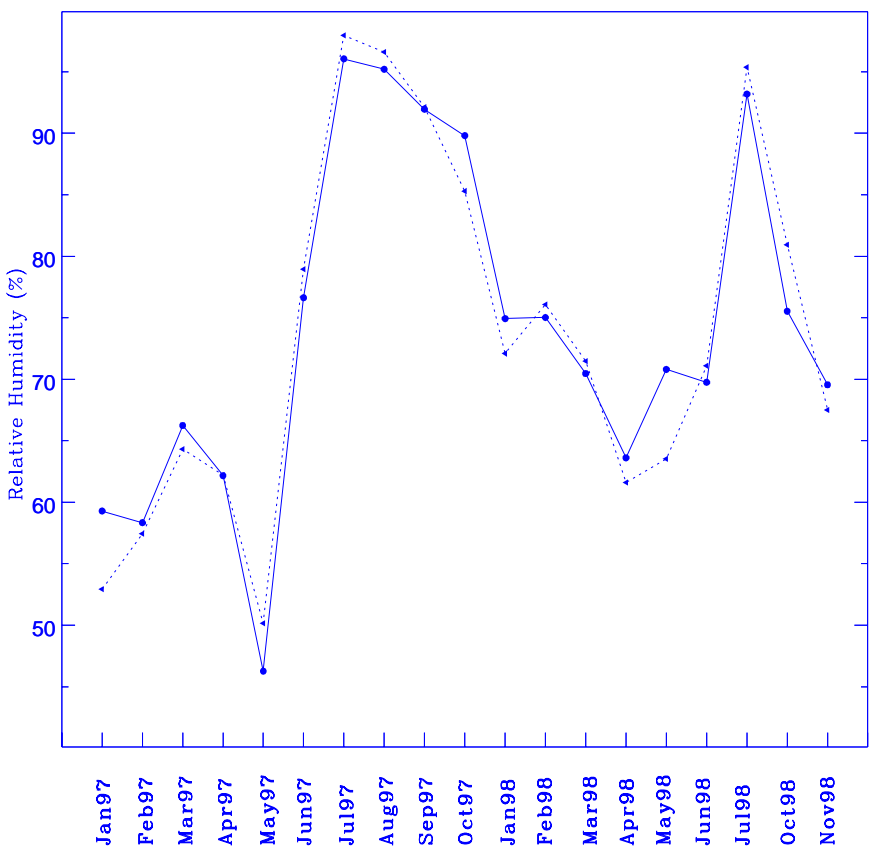

Fig. 10. Monthly variation of average relative humidity at Devasthal Site 1. The solid and dotted lines represent the relative humidity during day and night time respectively
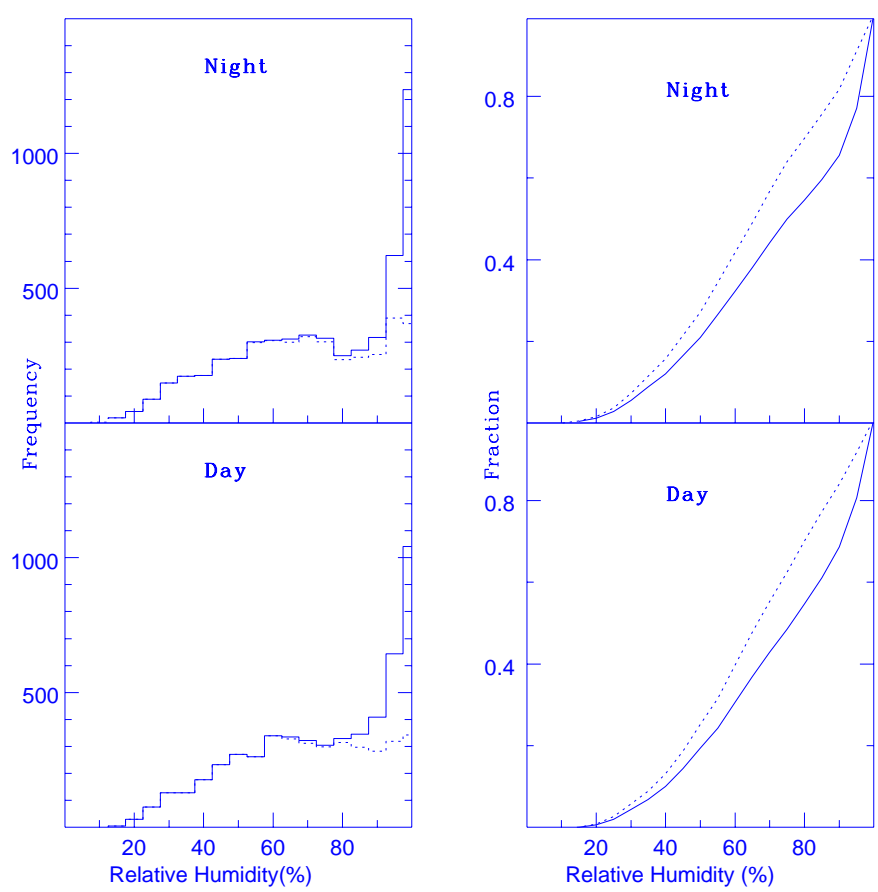

Fig. 11. Histogram and cumulative distribution of relative humidity at Devasthal Site 1. The solid line is for the whole data set, whereas the dotted line is for the data set excluding the monsoon months 
We have plotted in Fig. 3 the nightly variation of seeing against UT for Site 1 while the same for Site 2 has been plotted in Fig. 4. The statistical parameters obtained from seeing measurements for each month such as mean, median etc. are given in Table 3. They indicate that the seeing is relatively better during April, May and June as compared to other months. This tells us about a possible seasonal dependence of seeing, with summer months showing an average seeing better than other months. The monthwise histogram and cumulative distribution of seeing observations at Devasthal Site 1 and Site 2 are shown in Figs. 5 and 6 respectively.

\subsubsection{Comparison with test observations at UPSO}

A series of test observations with the $52 \mathrm{~cm}$ telescope, which was later shifted to Devasthal Site 1 was carried out for 18 nights at UPSO, during November and December, 1996. Figure 7 shows the histogram and cumulative distribution of seeing data obtained at UPSO which indicates a median value of $1^{\prime \prime} 6$. For comparison, corresponding plots for Devasthal sites are also shown in Fig. 7. Table 4 gives the overall statistics of the seeing values for the entire observing run at UPSO and Devasthal sites.

\subsubsection{Comparison of seeing at both Devasthal sites}

A Comparison of seeing measured quasi-simultaneously at both Devasthal sites on 8 nights during October and November 1998, is presented in Table 5. The differences in median seeing values range from 0 "' 16 to 1 "' 24 , with better seeing values always at Site 2 . Figure 7 , Tables 3 and 4 also indicate that Site 2 has better seeing values than Site 1. It is worth mentioning here that at Site 2 in comparison to Site 1 , for significantly large fraction $(\sim 40 \%)$ of the observing time seeing is $<1^{\prime \prime}$ (see Table 4 ). Another factor which favours Site 2 is that the seeing measurements were done at about $2 \mathrm{~m}$ above the ground level whereas at Site 1 it was carried at about $4 \mathrm{~m}$ above the ground. Studies by Pant et al. (1999), Vernin \& MuñozTuñón (1994) and Avila et al. (1998) indicate appreciable degradation in seeing due to turbulence introduced by the surrounding trees, local topography and ground radiation. The seeing improves considerably at height $\geq 10 \mathrm{~m}$ above the ground as discussed below.

\subsection{Microthermal measurements}

The detection of the local source of seeing degradation which occur in levels of the atmosphere very near the ground, within a few tenths of metres above ground is of great importance for evaluating the seeing conditions of an astronomical site. Microthermal fluctuations at Devasthal

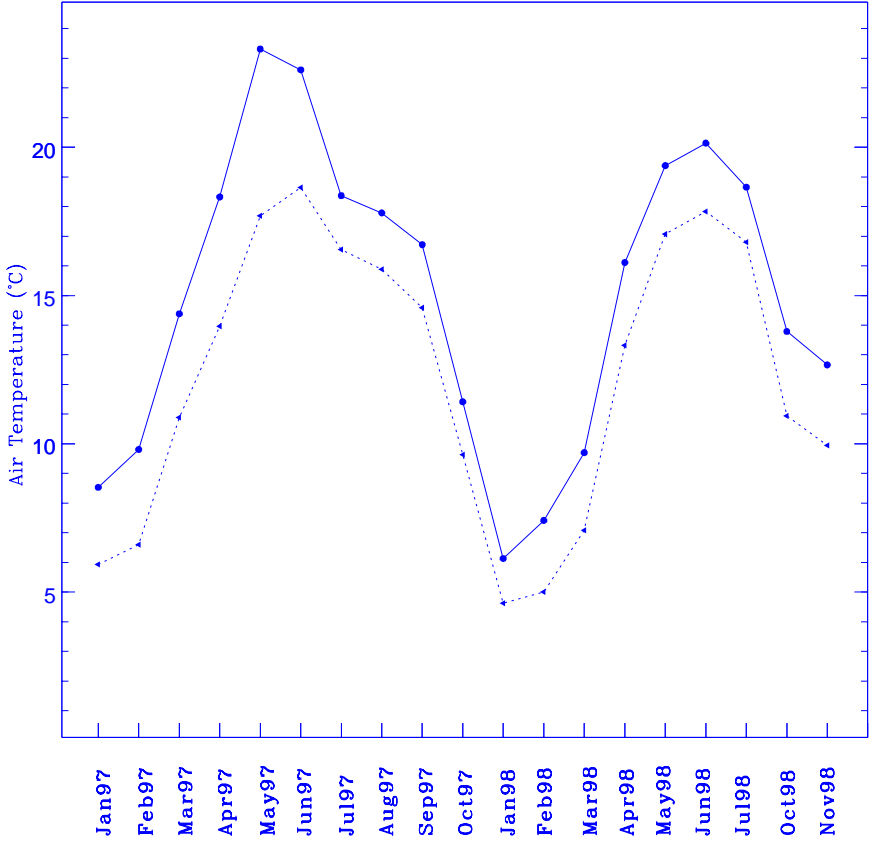

Fig. 12. Monthly variation of average air temperature at Devasthal Site 1. The solid and dotted lines represent the diurnal and nocturnal air temperature respectively

Site 1 were therefore recorded using pairs of microthermal sensors made from Nickel wire of $25 \mu$ in diameter separated by a distance of $1 \mathrm{~m}$ and mounted at three different levels on a mast situated respectively at 6,12 and $18 \mathrm{~m}$ above the ground. A description of the experimental setup and the methods employed in deducing the seeing estimates from the microthermal measurements can be found in Pant \& Sagar (1998) and Pant et al. (1999). Observations of the surface layer contribution to seeing were carried out during March to June 1998. The results of these observations have been reported by Pant et al. (1999) where they found that the major contribution to seeing comes from the $6-12 \mathrm{~m}$ slab of the atmosphere and sub-arcsec seeing of 0.65 and 0.5 can be achieved by locating the telescope at a height of $\sim 13 \mathrm{~m}$ and $18 \mathrm{~m}$ above the ground respectively. Similar conclusion about the degradation of image due to surface layer turbulence is also given by Vernin \& Muñoz-Tuñón (1994). There is a plan to carry out similar measurements at Devasthal Site 2 also.

\subsection{Meteorological all weather station}

Measurements of atmospheric parameters such as temperature, humidity, wind etc. simultaneous with DIMM and microthermal observations are of major importance in the interpretation of the atmospheric turbulence. To accomplish this a meteorological Automatic Weather Station (AWS) is also established close to the $52 \mathrm{~cm}$ telescope and the microthermal tower. The instrument is from $\mathrm{M} / \mathrm{s}$ 
Table 4. Seeing statistics at UPSO and Devasthal sites

\begin{tabular}{|c|c|c|c|}
\hline & UPSO & Site 1 & Site 2 \\
\hline Total no. of nights observed (datapoints) & $18(698)$ & $88(3698)$ & $37(6798)$ \\
\hline Minimum seeing $\left({ }^{\prime \prime}\right)$ & 0.5 & 0.5 & 0.5 \\
\hline Average seeing $\left({ }^{\prime \prime}\right)$ & $1.6 \pm 0.4$ & $1.5 \pm 0.4$ & $1.2 \pm 0.3$ \\
\hline Median seeing ("') & 1.6 & 1.4 & 1.1 \\
\hline Percentage of data with seeing $\leq 1$." 0 & 8 & 7 & 40 \\
\hline Percentage of data with seeing $1^{\prime \prime} 0-1^{\prime \prime} .2$ & 10 & 16 & 26 \\
\hline Percentage of data with seeing $1.2^{\prime \prime}-1{ }^{\prime \prime} 4$ & 16 & 22 & 17 \\
\hline Percentage of data with seeing $1.4^{\prime \prime}-1^{\prime \prime} 6$ & 18 & 21 & 09 \\
\hline Percentage of data with seeing $1 . .6-1$.". 8 & 17 & 12 & 04 \\
\hline Percentage of data with seeing $1^{\prime \prime} 8-2$.' 0 & 12 & 10 & 2 \\
\hline Percentage of data with seeing $>2 . .0$ & 18 & 12 & 2 \\
\hline
\end{tabular}

Champbell Scientific Inc. from U.S.A. It contains wind speed sensors, wind direction sensors, pyranometer for solar radiation measurement, temperature sensors for sensing the air and soil temperature, electronic tripping bucket rain gauge, relative humidity meter, solar panel for charging a 12 volt battery and data logger.

All the above instruments are mounted at the appropriate places on a mast fitted in a tripod. The tripod is kept upright and oriented, so one leg points due south, and then plumb the mast by adjusting south and northeast facing legs. The tripod including the mast is grounded with the help of a ground rod.

The instruments and the data logger are connected to a 12 volt battery to record the above mentioned meterological data automatically in a module. The data are stored in the module at one hour interval through programming. The capacity of the module is to store data for about a month. After a month the module is taken out of the data logger for processing and another module is connected for further recording. The meteorological data thus obtained are useful to see if there is any effect of these parameters on seeing. The histogram and cumulative distribution of day and night wind speed at Site 1 are shown in Fig. 8. It is found that both diurnal and nocturnal wind speed are less than $3 \mathrm{~m} / \mathrm{s}$ for $85 \%$ and $87 \%$ of the time respectively. The prevailing wind direction is mostly NW and it seldom exceeds $10 \mathrm{~m} / \mathrm{s}$. This is in agreement with our earlier observations(see Sect. 2.1.4). The distribution of wind speed and direction is shown in Fig. 9. The monthly statistics of average relative humidity are shown in Fig. 10 for
Table 5. A comparison of median seeing values measured at both Devasthal sites. Number of measured data points are given inside bracket

\begin{tabular}{|c|c|c|}
\hline \multirow[t]{2}{*}{ Data } & \multicolumn{2}{|c|}{ Median Seeing $\left({ }^{\prime \prime}\right)$} \\
\hline & Site1 & Site 2 \\
\hline 09/10/98 & $1.25(58)$ & $0.92(79)$ \\
\hline $11 / 10 / 98$ & $1.39(110)$ & $0.97(194)$ \\
\hline $28 / 10 / 98$ & $2.25(27)$ & $1.01(39)$ \\
\hline $01 / 11 / 98$ & $1.81(71)$ & $1.65(74)$ \\
\hline $05 / 11 / 98$ & $2.15(43)$ & $1.06(187)$ \\
\hline $11 / 11 / 98$ & $1.83(77)$ & $1.20(197)$ \\
\hline $12 / 11 / 98$ & $1.78(82)$ & $1.10(218)$ \\
\hline $13 / 11 / 98$ & $1.90(110)$ & $0.83(175)$ \\
\hline
\end{tabular}

both day and night. Figure 11 shows the histogram and cumulative distribution of relative humidity for the whole observing period. Both day as well as night time measurements indicate that $55 \%$ of the time, relative humidity lies below $85 \%$. However, this fraction increases to $70 \%$ if we exclude monsoon months from July to September. The monthly variation of nocturnal and diurnal average air temperature is given in Fig. 12. The difference between day and night average temperature is less than $3^{\circ} \mathrm{C}$ for all the months except March, April, May and June, where it is somewhat higher but still less than $6^{\circ} \mathrm{C}$. 


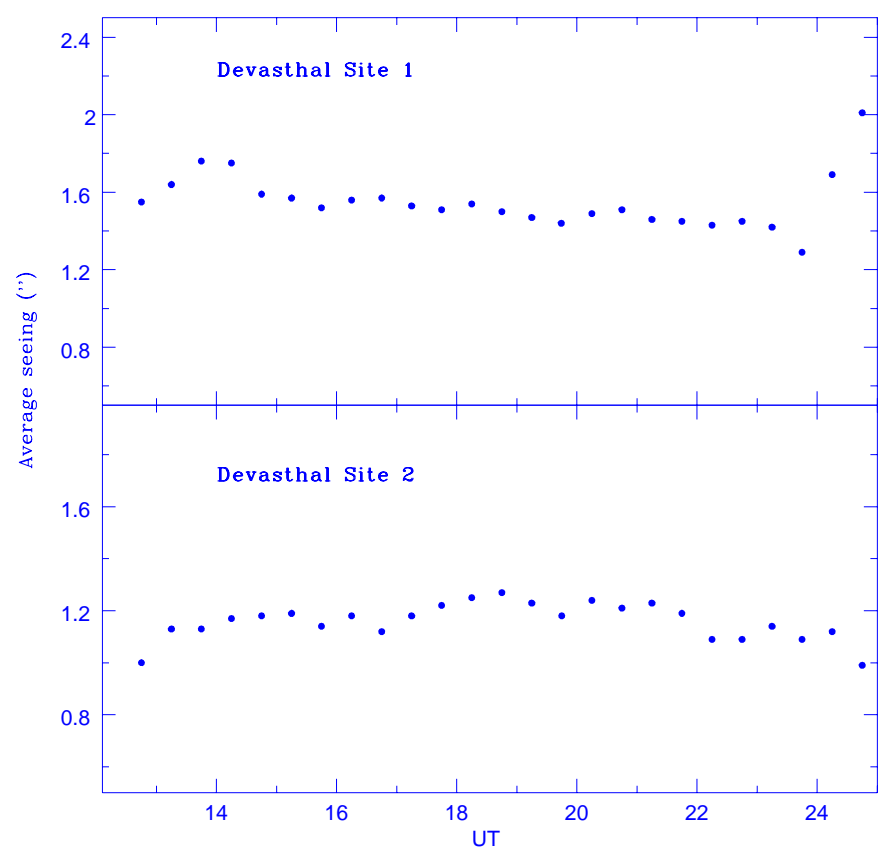

Fig. 13. Average seeing of $30 \mathrm{~min}$ duration versus UT for the entire observing period at Devasthal
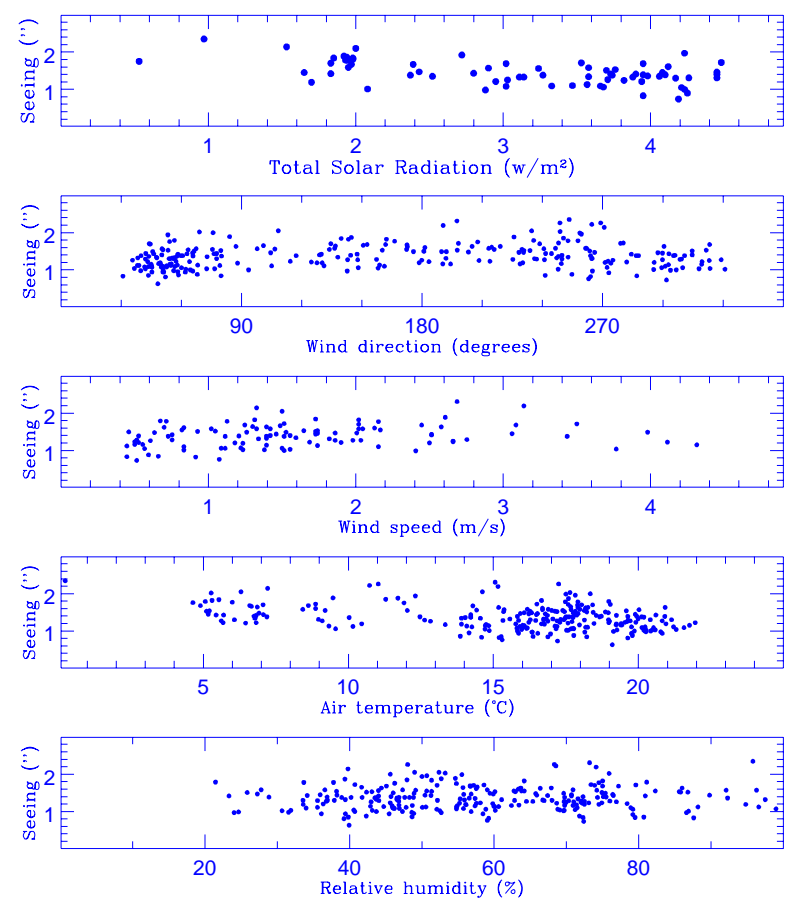

Fig. 14. Dependence of seeing on total solar radiation, wind direction, wind speed, air temperature and relative humidity at Devasthal Site 1

\subsection{Temporal evolution of seeing}

From the point of view of astronomers, it is useful to have a characterization of the temporal evolution of seeing, i.e., the variation of seeing quality with time. The results of all observing nights are averaged in 30 minutes bin and plotted against UT in Fig. 13 for Site 1 and Site 2. No significant trend is seen. This is in contrast with the generally prevailing notion among astronomers that seeing is poorer in the beginning of night and improves later in the night. Our results for Devasthal is in agreement with what has been found for the ORM site at La Palma by MuñozTunón et al. (1997), where no general trend in the seeing evolution is noticed.

\subsection{Dependence of seeing on meteorological parameters}

We have checked for possible relationships between the meteorology and the image quality for Devasthal site 1 . In Fig. 14, we have plotted the variation of seeing with meteorological parameters namely total solar radiation, wind direction, wind speed, air temperature and relative humidity. We observe that relative humidity does not seem to affect the seeing significantly. Weak correlation is noticed between air temperature and seeing, in the sense seeing improves at higher air temperature. A marginal dependence of seeing on total solar radiation is noticed with sunny days having better seeing. These are consistent with results given in Table 3, where seeing is better in summer months when air temperature is higher than that for rest of the year. The interesting plot concerns the wind speed and direction following the belief that these have an influence on the seeing. Correlation of wind speed is expected but not for low wind speed as the turbulence for wind speed less than $15 \mathrm{~m} / \mathrm{s}$ is relatively unimportant (Woolf 1982). Contrary to this, a weak correlation is noticed between seeing and wind speed and direction.

\subsection{Stability of seeing at Devasthal Site 2}

The stability of seeing with time tells us about the quality of the site To get a knowledge of the same we carefully looked into individual nights having more than 6 hours of continuous seeing data. This has been done only for Site 2 as it is better than Site 1. Among the 37 nights of observations at Devasthal Site 2 we have 25 nights which satisfied this criterion. The time during which seeing is less than $1^{\prime \prime}$. 0 in a stretch for $>4$ hour, 2 to 4 hour and $<2$ hour are found to be $10 \%, 47 \%$ and $43 \%$ respectively.

\subsection{Extinction measurements at Devasthal}

Routine extinction measurements in standard passbands were carried out using the $52 \mathrm{~cm}$ reflector equipped with a 
Table 6. Comparison of present seeing results with those of other sites

Site/Observatories Seeing $\left({ }^{\prime \prime}\right)$ Instrument Source

International sites

Mt. Graham, Arizona, U.S.A. $\quad 0.60$

Mt. Hopkins, Arizona, U.S.A. $\quad 0.59$

Las Campanas, Chile $\quad 0.60$

La Silla, Chile $\quad 0.87$

Paranal, Chile $\quad 0.64$

Mauna Kea, Hawai, U.S.A. $\quad 0.57$

La Palma, Spain $\quad 0.64$

SPM, B. C., Mexico 0.61

Freeling Heights, Australia $\quad 1.20$

Siding Spring, Australia $\quad 1.20$

\section{Indian sites}

\author{
UPSO \\ Devasthal Site 1 \\ Devasthal Site 2 \\ Leh \\ IUCAA, Pune
}

$\begin{array}{ll}\text { STT }^{a} & \text { Cromwell et al. (1998) } \\ \text { STT } & \text { Cromwell et al. (1990) } \\ \text { CM }^{b} & \text { Persson et al. (1990) } \\ \text { DIMM } & \text { Murtagh \& Sarazin (1993) } \\ \text { DIMM } & \text { Murtagh \& Sarazin (1993) } \\ \text { SCIDAR } & \text { Roddier et al. (1990) } \\ \text { DIMM } & \text { Muñoz-Tuñón et al. (1997) } \\ \text { STT, CM } & \text { Echevarria et al. (1998) } \\ \text { DIMM } & \text { Wood et al. (1995) } \\ \text { DIMM } & \text { Wood et al. (1995) }\end{array}$

DIMM

DIMM

DIMM

DIMM

DIMM

\author{
This work \\ This work \\ This work \\ Bhatt et al. (2000) \\ Das et al. (1999)
}

${ }^{a}$ Site Testing Telescope.

${ }^{b}$ Carneige Monitor.

${ }^{c}$ SCIntillation Detection And Ranging.

solid state SSP3 photometer. The lowest value of extinction was observed on 20 and 21 February, 1998. They are $0.40 \pm 0.01,0.22 \pm 0.01,0.12 \pm 0.01$ and $0.06 \pm 0.01$ in Johnson $U, B, V$ and $R$ bands respectively. A detailed paper on the atmospheric extinction measurements at Devasthal is published elsewhere (cf. Mohan et al. 1999).

\section{Discussion and conclusions}

From the observations taken so far, the following parameters have been obtained for Devasthal site:

1. In a year about $57 \%$ and $48 \%$ of nights are spectroscopic and photometric respectively;

2. Air temperature varies from $-4.5^{\circ}$ to $21.5^{\circ} \mathrm{C}$ in a year. However, variation during a night is $\leq 2^{\circ} \mathrm{C}$;

3. Relative humidity is below $60 \%$ during spectroscopic nights. However, during rainy season (end of June to middle of September) it goes to much higher values;

4. Pressure variation during a night is $\sim 1$ mbar;

5. Wind speed during night time is generally below $10 \mathrm{~m} / \mathrm{s}$. For about $85 \%$ of the time it is below $5 \mathrm{~m} / \mathrm{s}$. The prevailing wind direction is from NW to SE;

6. Average rainfall is $2000 \mathrm{~mm}$ in a year. Maximum rainfall could be $\sim 200 \mathrm{~mm}$ in 24 hour during rainy season;

7. Snowfall is for few days in a year;

8. Visual observations indicate that the sky at Devasthal is darker than that at UPSO where the values are 22.2 and $21.1 \mathrm{mag} / \operatorname{arcsec}^{2}$ in $B$ and $V$ photometric pass- bands respectively (cf. Bhargavi et al. 1998; Mohan 1998).

On the basis of above, we conclude that Devasthal is a good astronomical site except during rainy season. Results of DIMM seeing measurements carried out for 88 nights during 13 months at Devasthal Site 1, 37 nights during 3 months at Devasthal Site 2 and 18 nights during 2 months at UPSO are presented. The corresponding median seeing values are 1". 4,1 ."1 and 1".6 respectively. The DIMM instruments were operated in open air and hence there may not be appreciable contribution of the so called dome seeing to the seeing values reported here. But at the same time the difference in the temperature of the primary mirror and ambient temperature (the cause of the mirror seeing) and heat generated by structures near the telescope may affect the values reported here. Moreover as no corrections have been made for these effects and instrumental noise and the measurements carried out near the ground, the derived values are indeed upper limits. At site 2 , seeing is $<1^{\prime \prime}$ for $\sim 40 \%$ of the observing time in which a stretch of $>2$ hour is for $\sim 55 \%$. This study shows that Devasthal Site 2 is a good choice for locating the the proposed $3 \mathrm{~m}$ UPSO-TIFR optical telescope.

A comparison of our seeing results with those of other sites is given in Table 6 . It is worth pointing out that our seeing measurements at Devasthal Site 2 are carried out at $2 \mathrm{~m}$ above the ground level while seeing measurements at other places such as La Palma, SPM etc. have generally been carried out at larger heights from the 
ground. The seeing degradation due to turbulence introduced by the surrounding trees, local topography and ground radiative transfer has been analysed by Avila et al. (1998). This and the estimation of surface layer contribution to seeing using microthermal fluctuations at Devasthal Site 1, by Pant et al. (1999) indicate that most of the contribution to seeing come from the $6-12 \mathrm{~m}$ height. Pant et al. (1999) also concluded that sub arcsec seeing of $\sim$ of 0 .' 65 and 0 ". 50 can be achieved if the telescope is located at a height of $\sim 13 \mathrm{~m}$ and $18 \mathrm{~m}$ above the ground respectively. This indicates that sub arcsec seeing can be achieved for most of the time at Site 2 by putting the telescope at a height of $\sim 15 \mathrm{~m}$ above the ground. To quantify the gain in seeing with height, we plan to carry out microthermal measurements at Site 2. Further efforts will be made to characterise Devasthal Site 2 more precisely.

Acknowledgements. The valuable comments given by the referees Dr. Rafael Costero and Dr. J. Vernin are gratefully acknowledged which helped in improving the paper. The authors thank the UPSO team of scientific and technical staffs for their efforts put in the site testing campaign. The financial help rendered by Indian Institute of Astrophyiscs, Bangalore in the initial stage of this campaign is gratefully acknowledged. The authors thank the district and forest authorities for their help, Prof. Whestpal for providing us the water vapour meter and Indian Institute of Astrophysics for providing us the AWS. We thank Dr. H.S. Mahra and Dr. T.D. Padalia for their help during the site survey work. The authors thank the Survey of India for providing their contour maps

\section{References}

Avila R., Vernin J., Cuevas S., 1998, PASP 110, 1106

Bappu M.K.V., Mohin S., Unnikrishnan K.G., 1978, Kodaikanal Obs. Bull. Ser. A. 2, 168

Bhargavi S.G., Cowsik R., Pati A.K., Sagar R., 1998, BASI 26, 597

Bhatt B.C., Prabhu T.P., Anupama G.C., 2000, BASI 28 (in press)
Cromwell R.H., Haemmede V.R., Woolf N.J., 1998, in Very High Telescopes and their Instrumentation, ESO Conference Proceedings, Ulrich M.H., Vol. II, 917

Cromwell R.H., Haemmerle V.R., Woolf N.J., 1990, SPIE 1236, 520

Das H.K., Menon S.M., Paranjpye A., Tandon S.N., 1999, BASI 27, 609

Dierickx P., 1992, J. Mod. Opt. 39, 569

Echevarria J., Tapia M., Costero R., Salas L., Michel Rm., Michel Rl., Rojas M.A., Muñoz R., Valdez J., Ochoa J.L., Palomares J., Harris O., Cromwell R.H., Woolf N.J., Persson S.E., Carr D.M., 1998, Rev. Mex. Astron. Astrofis. 34,47

Forbes F.F., Morse D.A., Poczulp G.A., 1988, Opt. Eng. 27, 845

Fried D.L., 1966, J. Opt. Soc. Am. 56, 1372

Frieden B.R., 1983, in Probability, Statistical Optics and Data testing. Springer, Berlin, Heidelberg, New York, p. 248

HIROT team, 1996, BASI 24, 859

Mohan V., 1988, BASI 26, 367

Mohan V., Uddin W., Sagar R., Gupta S.K., 1999, BASI 27, 601

Muñoz-Tuñón C., Vernin J., Varela A.M., 1997, A\&AS 125, 183

Murdin P., 1985, Vistas Astron. 28, 449

Murtagh F., Sarazin M., 1993, PASP 105, 932

Pant P., Sagar R., 1998, BASI 26, 397

Pant P., Stalin C.S., Sagar R., 1999, A\&AS 136, 19

Pedersen H., Riguat F., Sarazin M., 1988, The Messenger 53, 8

Persson S.E., Carr D.M., Jacobs J.H., 1990, Exp. Astron. 1, 195

Roddier F., Cowie L., Graves J.E., Songaila A., Mckenna D., 1990, SPIE 1236, 485

Sadler E., Harrison S., Lee S., 1991, AAO Observers Guide

Sapru M.L., Kaul R.K., Bhat C.L., Mohapatra D.K., 1998, BASI 26, 655

Sarazin M., Roddier F., 1990, A\&A 227, 294

Tapia M., 1992, Rev. Mex. Astron. Astrofis. 24, 179

Vernin J., Muñoz-Tuñón C., 1994, A\&A 284, 311

Vernin J., Muñoz-Tuñón C., 1995, PASP 107, 265

Woolf N.J., 1982, ARA\&A 20, 367

Wood P.R., Rodgers A.W., Russel K.S., 1995, PASA 12, 97 